\title{
UMA DISCUSSÃO SOBRE A ANGÚSTIA \\ EM JACQUES LACAN: \\ UM CONTRAPONTO COM FREUD
}

Pedro Teixeira Castilho ${ }^{\star}$

\begin{abstract}
RESUMO
Em um primeiro momento este trabalho elucida a concepção de angústia no Seminário Livro 10: A angústia de Jacques Lacan. Depois de tal percurso, buscase comparar a noção da angústia como um afeto que não é sem objeto com a leitura freudiana de tal conceito. Finalmente, demonstra-se que é justamente esta concepção lacaniana de angústia que permite encontrar a noção de gozo e de desejo no objeto da angústia. As coordenadas para articular o desejo e o gozo convergem para a transmissão de gozo sendo anterior ao significante. Para demonstrar tal hipótese o autor propõe uma releitura do caso Hans de Freud

Palavras-chaves: Angústia. Afeto. Gozo. Desejo. Per version.

\section{A discussion about The anXiety in Jacques Lacan: AN OPPOSITION WITH FREUD}

Abstract

At first this work will show the conception of anxiety in the Seminary book 10: The anxiety written by Jacques Lacan. Secondly, it will place the idea of anxiety as an affection that is without object opposing freudian idea of anxiety. Finally, will point out the lacanian conception of anxiety offers an interpretation of the idea of beyond pleasure and desire presented in the anxiety's object. The coordination to manipulate de desire and the pleasure will converge to the transmission of the pleasure before the word. This new interpretation brings us to a new reading of the freudian interpretation of the Hans'case.
\end{abstract}

Keywords: Anxiety. Affection. Jouissense. Desire. Per version.

\footnotetext{
^ Mestre em Teoria da Literatura FALE - UFMG. Doutorando em Teoria Psicanalítica - UFRJ. Professor da graduação e da pós-graduação do ISTA: Instituto Santo Tomás de Aquino. Rua Itutinga, 300 - Bairro: Minas-Brasil -. Cidade: Belo Horizonte. Minas Gerais - Brasil. CEP: 30535-640. Tel.: Consultório: (031) 3281-9404.

E-mail: ctcastilho@ig.com.br
} 
Depois de Jacques Lacan dedicar uma lição no Seminário, livro 9: a identificação ao tema da angústia, ele sistematiza um saber sobre esse afeto no seu Seminário, livro 10: a angústia. Essa pesquisa é o divisor de águas entre a psicanálise freudiana e a psicanálise lacaniana. Nela, é proposto um saber sobre a angústia vinculado ao objeto a, que surge juntamente com este afeto. A relevância do Seminário, livro 10: a angústia é o esforço de Lacan em estipular a estrutura do objeto a, "a sua originalidade à teoria psicanalítica" (Lacan, 1962/2004, p. 375). A conseqüência de uma fundação do objeto a deve-se a um outro saber sobre os conceitos fundamentais da psicanálise: o inconsciente, a repetição, a pulsão e a transferência (LACAN, 1973, p. 21).

O ponto de partida do Seminário, livro 10: a angústia é o texto de Freud de 1926, Inibição, sintoma e angústia. Nele, o autor vienense recupera os seus clássicos casos do "Pequeno Hans" e "O homem dos lobos" para afirmar que; "em ambos os pacientes a força motriz da repressão (recalque) era o medo da castração" (FREUD, 1909/1975, p. 131). Com base nessa afirmativa, surge o axioma freudiano: "toda angústia é angústia de castração".

Ora, se existe uma diferença de abordagem entre Freud e Lacan acerca da angústia, esta pode estar situada na formulação da "angústia como angústia de castração", em Freud, e da "angústia como um afeto que não é sem objeto" (LACAN, 1962/2004, p. 84) em Lacan. Para Freud, a angústia paradigmática é a angústia de castração, ou seja, um ponto intransponível, seria o limite de toda análise (FREUD, 1937/1975, p. 247). Em contrapartida para Lacan, o ponto intransponível não será a angústia de castração propriamente dita, mas um fazer de sua castração aquilo que falta ao Outro.

A segunda ${ }^{1}$ investigação freudiana sobre a angústia é proposta a partir de Inibição sintoma e angústia, com o clássico caso do "Pequeno Hans". Para Freud, a fobia do pequeno Hans é o medo de cavalo; na imaginação da criança, um cavalo puxando uma carroça poderia mordê-lo. Em Freud existiria um conteúdo recalcado que se manifestaria como medo. Nesse caso, um ódio à figura do pai, o conteúdo recalcado, seria subjetivado pelo medo do cavalo que, como objeto de medo, teria uma suposta agressividade recalcada ao pai enquanto conteúdo latente. A criança não suportaria o ódio à figura do pai, substituindo-o pelo medo de cavalo. Sendo assim, teríamos uma atitude de ambivalência à figura do pai: o amor como conteúdo manifesto e, o ódio como conteúdo latente.

A angústia do pequeno Hans é o que ficou recalcado pela castração. O medo do cavalo é um substituto da idéia inicial de ser castrado pelo pai. A criança substituiu a angústia pelo medo e, a partir daí, Freud constrói "a angústia como angústia de castração" (FREUD, 1926/1975, p. 130).

Esse episódio, para Lacan, é um sinal de “desordem” (Lacan, 1962/2004, p. 16) que se configura como o sinal da angústia, mas, não a angústia propriamente dita. Do que trata, então, esse fenômeno na perspectiva lacaniana? Esse fenômeno, que terá um estatuto de afeto, assinala o encontro com o abismo, sua "manifestação é um grito" (LACAN, 1962/2004, p. 377) em que o mundo desaba. 
Lacan nos convida a fazer uma orografia da angústia, a descrição de um relevo e grafos, colocando a angústia em uma topologia, momento que o eu é lançado (jeté) $)^{2}$ da sua unidade e, o que surgir é o deslizamento de sua onipotência. Se, para Freud, a angústia estaria ligada a um objeto, como a agressividade ao pai, para Lacan, a angústia não é sem objeto. Cabe apontar o que levou Lacan a construir sua concepção de angústia enquanto "um afeto que não é sem objeto". Para tanto, a concepção de "afeto" e de "objeto" devem ser trabalhadas.

$\mathrm{Na}$ metapsicologia freudiana, o inconsciente teria sido constituído como um afeto preso a uma representação. Em cada produção do sujeito, existiria um conteúdo inconsciente, o afeto, para uma respectiva representação. No aparelho psíquico, há um correlato de afeto e representação; a teoria freudiana convoca o paciente a encontrar o representante do seu afeto. Esse afeto seria resultado da transposição de algumas idéias para outras que são simbolizadas no sintoma conversivo. Como acontece em uma conversão histérica, um afeto instala-se no corpo erógeno do sujeito. Na neurose histérica, há uma contenção do excesso da insatisfação do afeto nas conversões corporais. Na neurose obsessiva, o excesso de afeto sintomatiza-se na ruminação e na ação. E, na fobia de Hans, o afeto se liga a um objeto ou a uma situação determinada. A neurose, nesse caso, seria um afeto a deriva, sem representação.

"A angústia na rede de significantes", título escolhido por Jacques-Alain Miller para a primeira lição do Seminário, livro 10: a angústia de Lacan, interpreta a angústia como um afeto que se encontra a deriva entre os significantes. A "rede" seria aquilo que poderia capturar, uma "malha" que prende o que recebe o nome de angústia. Lacan cria um esquema para instaurar a angústia no campo do afeto. O que faz nesse primeiro capítulo é separar a emoção e a angústia, instituindo cada uma delas em condições diferentes de movimento e de dificuldade.

Usando a conceitualização feita por Freud em 1926, o psicanalista francês elabora o processo de diferenciação da libido na "inibição", no "sintoma" e na "angústia", todos colocados no mesmo quadro, mas, em posições subjetivas diferentes, como não si articulassem. Cada posição subjetiva teria um diferente estatuto. As três idéias tiradas por Lacan o "impedimento", o "embaraço" e a "comoção" é a distinção entre a angústia/afeto da emoção. A partir do eixo dificuldade e movimento a "angústia" estaria em registros diferentes de ação se comparados com a "inibição" e o "sintoma".

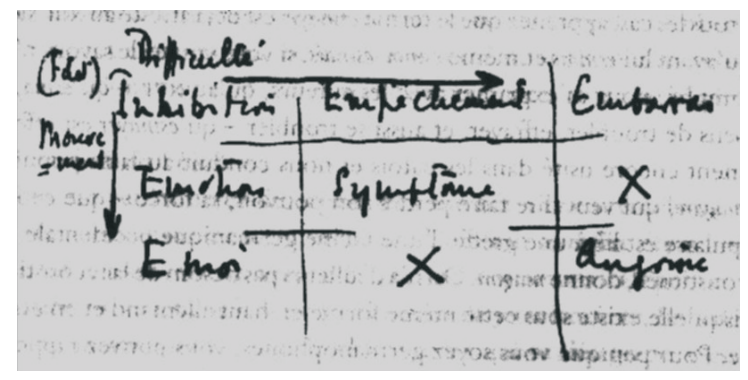

Figura 1: Lacan, 1962/2004, p. 22. 
Lacan situa a "inibição" como uma "paralisação" da libido, a inibição seria a libido sem "movimento". De um modo geral, as pessoas que são aprisionadas nesse estado sofrem uma diminuição nas suas aptidões locomotoras, a imagem construída do eu começa a perder o controle da situação. O sujeito inibido é aquele que não consegue sair de um lugar, se lançar em um projeto.

$\mathrm{Na}$ segunda coluna, Lacan busca a origem etimológica da palavra "impedimento", ele encontra a palavra "impedicare" cair em uma cilada, em uma armadilha, o sujeito está impedido porque está preso em uma armadilha, a cilada é a captura narcísica. Pois, como pretendo demonstrar, aquilo que coloca o sujeito em "movimento" é justamente "a falta de alguma coisa na imagem". Quando o sujeito se identifica com a imagem é porque o sujeito recua diante da castração (simbólico), e cai na cilada imaginária.

Quando o "movimento" é menor e a "dificuldade" é maior existe o embaraço. Lacan faz referência à palavra "embarazada", do espanhol, "estar grávida". Esse termo se refere a uma "forma de angústia", o sujeito vive uma divisão subjetiva. Verifica-se que tanto na inibição como no embaraço existiria uma ausência de "movimento", mas, como o quadro revela, na inibição a "dificuldade" está ausente.

Já a "emoção", que será trabalhada como "comoção" no português, subjetivados como perturbação e inquietude. Esta "emoção" também encontra uma referência etimológica, se trata de um "movimento", uma agitação, um movimento que desagrega, ou seja, uma comoção, comover ou tirar do lugar. Lacan descarta a angústia como uma emoção, a angústia seria uma comoção sem relação com o simbólico.

A angústia estaria no último termo que teria o máximo de "movimento" e o máximo de "dificuldade" no grafo, presente quando não se sabe mais o que fazer, quando não há em que se agarrar.

Na passagem do texto Le ravissement de Lol V. Stein (DURAS, 1986, p. 64) escrito por Marguerite Duras, a protagonista Lol se encontra em um instante eterno, quando entra no salão de festas e vê seu amado, Michel Richardson com Anne-Marie Stretter. Um instante de esvaecimento subjetivo, em que não há a que se agarrar, ocorrendo toda uma organização fantasmática a partir dessa cena (LACAN, 2001, p.191).

Quando adolescente Lol perde o noivo Michel Richardson para AnneMarie Stretter em um baile na sua cidade, quando vê a cena do noivo com outra mulher Lol abaixa os olhos para depois acompanhar o casal com o olhar e, em seguida, desmaiar. Lol se casa com outro homem e muda-se de cidade, resolve ter filhos e aparenta ter uma vida tranqüila. Depois de dez anos retorna a cidade e vê um homem caminhando com uma mulher que lhe parecem familiar. Depois deste episódio, o passado retorna para Lol, ela não sabe mais diferenciar o sonho da realidade.

Em Hommage fait à Marguerite Duras Lacan propõe este instante do olhar, momento em que Lol se coloca como protagonista da cena, como o apoio de Lol 
durante os próximos dez anos, um momento em que sua posição subjetiva se ancora se fazendo olhada, les centre du regards (LACAN, 2001, p. 193).

Diferentemente da análise freudiana sobre a angústia, em Lacan este afeto não se apóia em nada. Se para Freud a metapsicologia sobre a angústia gira em torno de um objeto: o rochedo da castração, a angústia em Lacan é proposta diante de um não saber fazer diante da falta do Outro, ou seja, é da inexistência de um significante da falta do Outro que se trata.

Ou seja, para compreender essa noção de falta teríamos que investigar a dimensão afetiva desta falta. O afeto da angústia "não se apóia em nada". Lacan recupera uma construção lingüística para negar o caráter ôntico da angústia e, afirmá-la enquanto um afeto que não é sem objeto. A angústia não é sem objeto porque não tem uma maneira de satisfazer-se na sua plenitude. Isso é encontrado na retórica como a "função da litotes" e, justamente o que uma "litotes" traz à tona é a idéia de que, embora pareça que não tem, existe. Embora pareça que não há objeto, esse objeto existe. Logo, a angústia é definida pela anulação do significante, pois, "isso não equivale a dizer que esse objeto seja apenas o avesso da angústia, mas que ele só intervém, só funciona em correlação com a angústia" (LACAN, 1962/2004, p. 98).

Nesse ponto, Lacan utiliza a metáfora do louva-a-deus, em uma referência ao ato sexual desse inseto, dizendo que a fêmea, depois do ato sexual, devora o louva-a-deus macho. Tal metáfora evoca a condição de angústia do sujeito diante da falta do significante no campo do Outro. A questão da angústia estaria concentrada no enigma do sujeito no campo do Outro.

Suponham-me em um recinto fechado, sozinho com um louva-a-deus de metros de altura. É uma boa proporção para que eu tenha a altura do louva-a-deus macho. Além disto, estou vestindo a roupa de um louva-a-deus de $1,75 \mathrm{~m}$, mais ou menos a minha altura. Eu me olho, miro minha imagem, assim fantasiado, no olho facetado do louva-a-deus. É isto a angústia? Está bem perto. Trata-se da apreensão pura do desejo do Outro como tal, uma vez que justamente ignoro minhas insígnias, pois estou ridiculamente vestido com a mortalha do varão. Não sei o que sou como objeto para o Outro (LACAN, 1962/2004, p. 39).

No campo do Outro, haveria algo que falta. Aqui, teríamos o aspecto inovador da temática da angústia. É por isso que, para Lacan, não há acesso ao desejo, não há sustentação possível que não seja por meio da angústia construída a partir da falta do Outro. Se para Freud, o sujeito esbarra em um ponto intransponível, em Lacan o ponto intransponível é uma construção subjetiva do significante da falta do Outro. Essa sustentação possível do desejo supõe a relação ao objeto que se configura na relação com o Outro. Relação, nesse caso, que é mediada pelo registro da fantasia, ponto intransponível para Freud. É justamente a partir da experiência de indeterminação que é colocado o sujeito. A metáfora do louva-a-deus é a idéia de que existe um não saber diante da falta do Outro, diferentemente de Freud, que constrói a idéia de um obstáculo intransponível para a angústia, como o Pai do pequeno Hans ou o rochedo da castração. Em Lacan não se pode 
saber sobre a falta do Outro, a angústia seria a falta da falta. Diante da inexistência de um saber sobre a falta do outro se angustia. Neste ponto é que Lacan avança no saber sobre a angústia.

A angústia é o sinal do direcionamento da cura do paciente, a bússola que aponta para aquilo de mais estranho (Unheimlich) na sua experiência analítica, mas também para aquilo de mais íntimo, sua "ex-timidade". Um "sinal" (LACAN, 1962/2004, p. 185) daquilo que o sujeito evita e que define a sua verdade (BAAS, 2001, p. 56) com relação ao seu desejo, um afeto que não engana na direção da cura em psicanálise.

O que estaria em causa nesse seminário seria o estatuto do objeto do desejo, isto é, aquilo que instaura o desejo, que atrai o desejo do sujeito; devemos passar pelo estatuto do objeto da angústia. A angústia não é pensada em si, não é recortada como um objeto de investigação, é pensada como uma passagem de uma dimensão a outra.

Na terceira lição, "Do cosmos a Unheimlichkeit", há marcações no capítulo: o mundo e a cena do mundo; a relação especular do significante; e, por último, Hamlet e a cena sobre a cena.

Na primeira passagem, é a determinação desse objeto de angústia, na dimensão escópica, que estabelece o estatuto do objeto $a$. Uma maneira de introduzir essa questão seria buscar apoio nas referências freudianas para recuperar a problemática da angústia como via de acesso. O texto de Freud, "Um distúrbio de memória na Acrópole", é o ponto de apoio. Freud escreveu esse texto em homenagem a Roman Rolland. Retomando uma viagem que fez com seu irmão mais novo, até a Itália, Freud sugeriu que fossem até a Grécia, onde teriam mais condições de viabilizar o passeio, por causa de alguns impedimentos na Itália. Os dois irmãos vão para Atenas e, em determinado momento, em que Freud está no alto da Acrópole, vendo aquele cenário, ele é atravessado por uma idéia:

Quando por fim na tarde da nossa chegada eu me encontrava na Acrópole e pousava meus olhos sobre o cenário, um pensamento surpreendente, uma idéia estranha passou rápido em minha mente, e a idéia é esta: então tudo isto existe mesmo. Tal como aprendemos no colégio. (FREUD, 1936/1975, p. 292).

Alguma coisa do ponto de vista do campo escópico se apresentou aqui para Freud e teve um efeito de divisão. Ao comentar "então, tudo isto existe mesmo", o próprio Freud vai puxando o desdobramento dessas elaborações, que é o efeito que se tem quando somos confrontados por alguma coisa excessiva. Qual seria o estatuto disso que apresentou Freud, nesse momento, na Acrópole? Lacan designa essa experiência como um vislumbre do objeto. De um objeto que se rompe e que se apresenta, normalmente, na angústia, e que poderia permitir acesso à dialética do desejo, simplesmente para constatar a presença desse objeto, também como poderia dar acesso ao desejo. 
Nessa terceira lição, o objeto é pensado a partir do campo imaginário, da dimensão escópica. Por que Lacan passa pelo imaginário para introduzir a angústia? A necessidade de percorrer o escópico para conferir esse objeto é que ele se configura como objeto estranho. A estranheza daquilo que se apresenta tem quase um estatuto de objeto. De alguma maneira, a via do imaginário seria propícia para perceber esse objeto que se apresenta no campo escópico e no campo visual, sendo necessário reformular a concepção anterior que se tinha sobre o imaginário. A idéia do imaginário apoiada sobre o estádio do espelho não seria suficiente para nos darmos conta da dimensão do objeto que se apresenta na angústia. Lacan fez uma passagem do estádio do espelho ao esquema ótico. No estágio do espelho temos a ilusão de que a pulsão está ligada à imagem, na passagem para o esquema ótico Lacan cria o furo.

O que é fundamental na distinção do estádio do espelho para o esquema ótico é que há uma máquina que tem dois espelhos, um convexo do lado esquerdo e um plano no meio.

Aquilo que acontece do lado esquerdo, não necessariamente se reproduz no lado direito. Essa é a primeira distinção no modo de se pensar o campo do imaginário que, até então, havia sido pensado a partir do operador espelho. Aqui, nessa complexificação do esquema ótico, tem-se um modo de pensar no campo escópico, o campo do imaginário. É nessa assimetria (aquilo que se apresenta de um lado do espelho não necessariamente vai se encontrar no lado oposto) que vamos ver que há um lugar no campo imaginário para se perceber o objeto da angústia. A idéia do estádio do espelho, numa relação narcísica, é a de pensar que tudo aquilo que está do lado do real está também presente nesse outro lado.

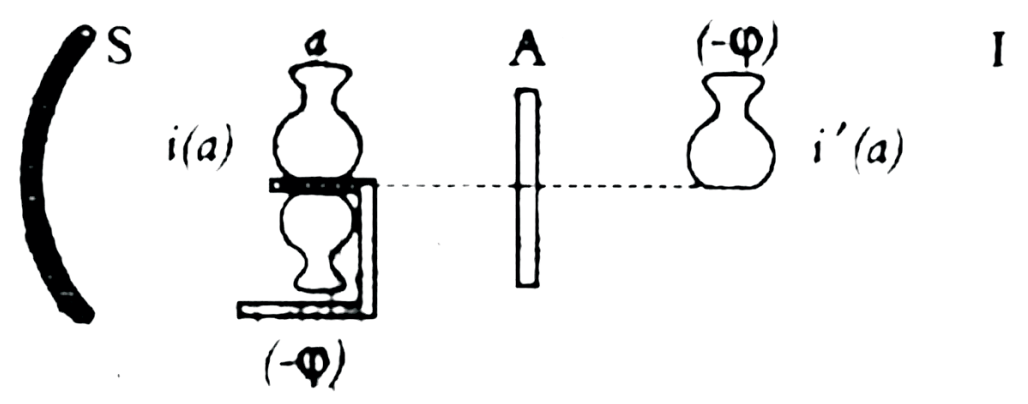

\section{Schéma simplifié}

Figura 1: Lacan, 1962/2004. p. 50.

Lacan comenta, na lição "Do Cosmos a Unheimlichkeit", um trecho do Hamlet, de Shakespeare. Por que Lacan faz referência ao Hamlet nesse momento? A referência é a uma cena dentro da cena, o que os comentadores de Hamlet têm como uma peça sobre a peça, que é the play inside the play. A peça inicia-se com uma visita do fantasma do pai de Hamlet comunicando que ele teria sido morto 
pelo tio Cláudio que, alguns dias depois, casa-se com a esposa do pai, Gertrude, e assume o reino. Hamlet é convocado a vingar essa ação para tomar o trono, novamente, do tio usurpador. Então, o drama é uma série de atitudes de Hamlet em relação ao que ele faria, e mesmo como confiar na palavra do fantasma. Hamlet, então, para confirmar essa culpa do rei, e apreendê-la, lança mão da encenação de uma peça, dentro do castelo, com um grupo de atores que estava passando por lá. Ele toma esse grupo de atores e conversa com eles, sugerindo que seja encenada uma peça que se chama "A morte do acusado", que ele designa como uma "armadilha"; o título da peça é "Ratoeira", não para pegar um rato, mas, na verdade, um rei que podia estar incriminado. Nessa cena, alguma coisa também se introduz no lugar que deveria permanecer vazio e podemos perceber isso nos efeitos que a cena produz no personagem do rei assassino.

$\mathrm{Na}$ encenação da peça, o rei é morto com gotas de veneno despejadas em seu ouvido pelo próprio irmão. O ponto que chama a atenção é que a pessoa que é chamada para representar o assassino está numa posição exatamente homóloga à do próprio Hamlet, que, na verdade, é sobrinho do rei. Hamlet encena o próprio ato parricida o que é um detalhe bastante interessante.

Ora, se para Freud a angústia de castração esbarrar no rochedo, percebese que Lacan institui um furo no rochedo da castração com o objeto $a$, e, quais seriam as conseqüências disto na constituição do sujeito lacaniano?

A resposta é o desejo do Outro, e, é a falta do "Outro que é aquela que me vê". (Lacan, 1962/2004, p. 79). A angústia é o sinal para o desejo do Outro que já esta antes do sujeito, o próprio objeto, causa de desejo e de gozo.

Estamos nos cinco desdobramentos do objeto $a$ : oral; anal; genital; escópica e invocante. É aqui que Lacan se debruça para apontar as manifestações do objeto no corpo erógeno. O corpo com buracos contornados pelas bordas libidinalizadas e erotizadas pela interpretação que o sujeito faz da falta do Outro: orifícios erógenos tangenciados por zonas libidinais que foram batizadas por Karl Abraham (1970) de objetos parciais. Freud (1905/1975) inicia o trabalho das pulsões parciais nos "Três ensaios sobre a teoria da sexualidade", a fase oral (canibalismo), a fase anal (primitiva) e a fase fálica (genital), para demonstrar as fases de desenvolvimento da libido que se organiza de forma definitiva a partir da fase fálica. ${ }^{3}$ Em Lacan (1962/2004), a sexualidade se constitui em torno do buraco, da falta que circula o buraco vazio do objeto. De que tratam os objetos parciais em Lacan?

É esta a maleabilidade das zonas que contornam o corpo como cicatrizes indeléveis a partir da ausência de significação da falta do Outro. Diferentemente de Freud, para Lacan estas zonas libidinais não se constituem a partir de etapas, como foram inicialmente introduzidas por Freud e posteriormente radicalizadas com o ensino dos pós-freudianos. Situam-se como uma falta que o sujeito interpreta da falta do Outro, ou seja, é o gozo do Outro que impele a pulsão em uma cadeia de "significação" ativa. Neste momento do ensino de Lacan, é da falta deste significante do Outro, que emerge o sujeito, uma interpretação que o sujeito faz do gozo do Outro que contorna o vazio do objeto. A consistência do objeto é o 
vazio, é nada. Lacan reduz o objeto $a$ a algo que não se substancializa, traduzido em formas homólogas ao olhar, à voz, ao oral e ao anal. Delimitações de bordas que são circunscritas pela falta do Outro.

Se em um primeiro momento percorreu-se a angústia a partir da metapsicologia situando este afeto diante do significante, agora é o objeto causa da angústia, o objeto $a$, um vazio que é marcado pelo desejo do Outro que humaniza o sujeito falante, a falta do Outro erotiza o vazio do objeto.

Na pulsão escópica é aludida a figura de Buda, uma estátua em que Lacan observa suas pálpebras, através das quais seria difícil descobrir o sexo deste sujeito. Seria ele "Homem ou Mulher" (LACAN, 1962/2004, p. 266)?

Este olhar de Buda é a articulação do desejo com a imagem, cria-se o desejo como uma ilusão e, um ponto vazio nesta ilusão que não é especularizável. Uma diferença nítida entre o olho e do olhar começa a ser delineada pela psicanálise lacaniana. O começo de um desejo como ilusão e o vazio não especular do objeto.

Se não se sabe se Buda é Homem ou Mulher é por causa do ponto de anulação do seu olhar. Estas pálpebras são um espelho da ilusão, existindo algo de engano e de miragem no uso da pulsão escópica. Seu olhar não traz nenhuma marca sobre o sexo, podendo ele ser homem ou mulher.

O olhar do Outro só se torna um objeto de reconhecimento a partir do momento que existe uma subjetivação da imagem, dando vida, como um brilho no olhar, um momento nulo do olhar, o instante zero (LACAN, 1962/2004, p. 293). Na parábola do conde de Wladwostock, o vampiro não se reconhece no espelho exatamente porque não existiu um outro para criar a ilusão do seu desejo e da imagem do seu Eu.

O desejo é ilusório. Por quê? Porque se dirige sempre para o outro lugar, para um resto, para um resto constituído pela relação do sujeito ao outro que vem se substituir aí (LACAN, 1962/2004, p. 276).

O desejo do Outro oculta a castração, o ponto zero ausente de qualquer significação, um buraco esvaziado de gozo que se suporta pela castração, em termos lacanianos. O vampiro não foi humanizado pelo desejo do Outro porque sua imagem narcísica é sem apoio de sustentação do desejo. Este objeto parcial de Lacan é o suporte do sujeito na formação imaginária de seu desejo, a "falta do Outro como aquela que me vê". ${ }^{4}$

Com relação ao objeto voz, Lacan investiga o instrumento do shofar, o primeiro instrumento de sopro na história do judaísmo que quando soprado emite um som contínuo fora de qualquer tom. A razão deste instrumento na história do cristianismo é de estabelecer o pacto entre o povo hebreu e Yavé.

No Seminário Livro 10: A angústia, a Lição XVIII - A Voz de Javé, Lacan comenta o texto de Théodore Reik sobre o shofar, o som de um instrumento confeccionado com chifre de animal que se toca três vezes na sinagoga depois do Rosh Hashanah ou Yom Kippour, no dia do perdão, o primeiro dia do ano do calendário judeu. 
Para Théodore Reik, o uso desse instrumento visa marcar a renovação do pacto que liga Javé com o povo judeu. O shofar é o ponto de amarração para a elaboração do objeto voz, e que na verdade aparece aqui através desse shofar cuja apreensão, da parte do Reik, visa mostrar que se trata de um mugido, tendo algo de primitivo em sua fabricação que não é refinada, um instrumento que é quase retirado do animal, produzido com parte de seu corpo, seu chifre, seu osso.

Com a construção do objeto $a$ retomo o caso do Pequeno Hans para aproximar o objeto $a$ no circuito da satisfação pulsional de Hans. A proposta freudiana de interpretar o sintoma fóbico de Hans enquanto um deslocamento da agressividade recalcada ao pai poderia ser substituída pela noção lacaniana da falta do Outro. Ou seja, uma interpretação de Hans com Lacan nos conduziria a interpretar o sintoma da fobia de Hans a partir do gozo do pai de Hans.

O pequeno Hans padecia de seu sintoma justamente quando a diferença sexual se inscreve no seu inconsciente, seres inanimados não teriam o "pipi" e seres animados teriam o "pipi”. Depois deste episódio aparece a dúvida de Hans sobre sua mãe, será que ela teria o pipi ou não o teria? Esta dúvida sobre a presença ou ausência de "pipi" é ampliada aos cavalos, segundo Freud este deslocamento para os cavalos deve-se a uma cena vivida por Hans, a primeira pessoa que serviu a Hans como um cavalo devia ter sido seu pai. Quando a repressão (recalque) começou e trouxe consigo uma revulsão de sentimentos, os cavalos que tinham sido associados com tanto prazer, foram necessariamente transformados em objetos de medo (FREUD, 1913/1975, p.115).

Este deslocamento do sintoma de Hans para os cavalos passa a ser sua principal queixa, e simultaneamente o medo dos cavalos vai-se "transmutando gradativamente em uma compulsão para olhá-los: ele (Hans) dizia: Tenho que olhar para os cavalos e aí fico com medo" (FREUD, 1909/1975, p. 133). No entanto, com Lacan, não seria Hans que olha para os cavalos e sim, os cavalos que olham para Hans porque algo do sujeito Hans se manifesta nos cavalos. A maneira que Hans subjetiva seu sintoma deve-se a uma estranheza que se intensifica com a presença de um cavalo. Esta é a "ex-timidade" de Hans, algo estranho que também é familiar.

Depois do limite da interpretação que Freud faz deste caso, "que ele (Hans) se incomodava, em particular, com aquilo que os cavalos usam à frente dos olhos, e com o preto em torno de suas bocas - certamente não se explicariam a partir daquilo que sabíamos" (FREUD, 1913/1975, p. 44), do objeto $a$, que Lacan traz à tona a partir do Seminário Livro 10: A angústia, é para o pequeno Hans a mancha que resiste no sintoma fóbico, está mancha também se manifestava em uma estranheza do bigode do cavalo, "o preto em torno da boca do cavalo significava um bigode" (FREUD, 1913/1975, p. 45).

Um ponto obscuro de cristalização no nível escópico é o que os cavalos da cena fóbica têm diante dos olhos e o negro que existe em torno de suas bocas. É aí, na relação do pai e do filho que a interrogação diante dos olhos e o negro na boca do cavalo se constituem. Freud analisou os dois, pai e filho, para localizar uma simetria entre alguma coisa que diz deste par. Existe um recalque entre o pai 
e o filho que estrutura o quadro familiar, Hans faz alusão àquilo que olha para ele e, isso que o olha é o gozo do próprio pai, que faz borda diante do vazio. Não mais uma agressividade recalcada do pai, mas, sim o gozo do pai que se sintomatizam no olho na boca do cavalo, objetos parciais do animal: olho e boca.

O objeto $a$, em seu paradoxo essencial, é o objeto da angústia. Passando pela negação: "ela não é sem objeto", ele institui Hans em um círculo pulsional conduzido pelo gozo do pai. O bigode do pai é o sinal da falta do pai de Hans. Hans sintomatiza este gozo no cavalo por não saber criar um saber para a falta do pai. Sendo assim, a vertente de amor ao pai em Hans se manifesta tendo em contra partida a vertente de ódio ao pai de Hans, o recalcado. No entanto, a leitura lacaniana permite abordar o pecado do pai, seu gozo.

O que angustia Hans na sua posição subjetiva é o que nos conduz para seu gozo, ou seja, a angústia é a via de acesso privilegiada ao objeto $a$. Dizemos que a angústia corresponde à captura deste objeto $a$ no fantasma de Hans que denuncia o gozo de seu pai, a per-version. Este é o momento eterno que esse sujeito se encontra, então suspenso, paralisado, em um fading infinito, onde ele faz a experiência dolorosa de sua própria divisão. Isto é o que foi descrito como fenômeno da angústia.

Angústia-sinal que não deve ser entendida como sinal para o sujeito. Se assim o fosse, a angústia não seria causa do recalque, como Freud o formula em seu texto "Inibição, sintoma e angustia", mas, justamente, o contrário. Se a angústia não é sinal para o sujeito é porque ela é sinal do próprio furo que se instala na satisfação pulsional, sinal do objeto de satisfação que se apresenta como perdido.

\section{Notas}

${ }^{1}$ Não cabe aqui desenvolver a primeira investigação teórica sobre a angústia em Freud.

${ }^{2}$ Mantivemos o jeté - porque em francês podemos entender o sujeito jogado para fora de sua unidade.

${ }^{3}$ É importante apontar que Lacan se esforça em teorizar a natureza simbólica do falo. Essa natureza simbólica da organização genital reflete um esforço lacaniano de escapar de toda denotação biológica dessa organização. Ou seja, o falo, a partir de Lacan, passa a ser um significante, contrapondo-se a algumas leituras pós-freudianas, pelas quais o falo tem uma correspondência com a anatomia. No seminário "A relação de objeto", Lacan (1995) articula o falo a um produto da metáfora paterna e, no texto "A significação do falo", de 1998, o falo passa a ser interpretado como significante.

${ }^{4}$ Lacan (1990) explora o conceito de anamorfose de um quadro de Holbein, existe um erro de visão do quadro, não vemos o quadro de uma maneira objetiva, neste conceito existe algo meu no quadro que atrai o sujeito que olha para a obra. Barthes $(1984$, p. 25) exemplifica isso na sua obra A câmara clara: "o punctiom no quadro é o que me atrai em uma fotografia, como se algo nos olhasse, um buraco que atrai o sujeito, um buraco vazio. O contorno da obra é uma ilusão que se ancora no vazio. A obra seria uma ilusão criada em torno do que me olha". 


\section{REFERENCIAS}

ABRAHAM, K. Teoria psicanalítica da libido. Rio de Janeiro: Imago, 1970.

BAAS, B. O desejo puro. Rio de Janeiro: Revinter, 2001. Coleção Freudiana.

BARTHES, R. A câmara clara. Rio de Janeiro: Nova Fronteira, 1984.

DURAS, M. O Deslumbramento: le ravissement de Lol V. Stein. Tradução Ana Maria Falcão. Rio de Janeiro: Nova Fronteira, 1986.

FREUD, S. Inibição, sintoma e angústia: um estudo autobiográfico (1926). In: . Obras Psicológicas Completas de Sigmund Freud. Rio de Janeiro: Imago, 1991. v. XX. Edição Standard Brasileira.

. Um caso de histeria. Três ensaios sobre a teoria da sexualidade e outros trabalhos (1901-1905). In: Obras Psicológicas Completas de Sigmund Freud. Rio de Janeiro: Imago, 1975. v. VII. Edição Standard Brasileira.

. Duas histórias clínicas: (O pequeno Hans e o homem dos ratos) (1909). In: _. Obras Psicológicas Completas de Sigmund Freud. Rio de Janeiro: Imago, 1975. v. X. Edição Standard Brasileira.

- O retorno do totemismo na infância (1913). In: . Obras

Psicológicas Completas de Sigmund Freud. Rio de Janeiro: Imago, 1975. v. XIII. Edição Standard Brasileira.

. Um distúrbio de memória na Acrópole (1936). In: . Obras

Psicológicas Completas de Sigmund Freud. Rio de Janeiro: Imago, 1975. v. XXII. Edição Standard Brasileira.

. Análise terminável e interminável (1937). In: . Obras Psicológicas

Completas de Sigmund Freud. Rio de Janeiro: Imago, 1975. v. XXIII. Edição Standard Brasileira.

LACAN, J. O Seminário, livro 4: a relação de objeto. Rio de Janeiro: J. Zahar, 1995. . (1961-62) O Seminário, livro 9: a identificação. Inédito.

. Le Seminaire, livre 10: l'angoisse. Paris: Seuil, 1962/2004. Le champ

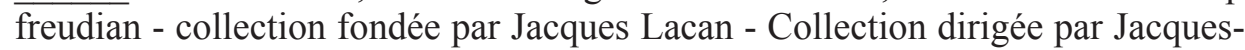
Alain et Judith Miller. 
LACAN, J. O Seminário, livro 11: os quatro conceitos fundamentais da psicanálise. Rio de Janeiro: J. Zahar, 1990.

. A significação do falo. Tradução Vera Ribeiro. In: . Escritos. Rio de Janeiro: J. Zahar, 1998. p. 692-703.

. Autres écrits. Paris: Seuil, 2001. p. 191-197. Le champ freudian collection fondée par Jacques Lacan - Collection dirigée par Jacques-Alain et Judith Miller. Hommage fait à Maguerite Duras, du ravissement de Lol V. Stein.

Recebido em: outubro de 2005 Aceito em: abril de 2006 